\title{
Health and nutritional status of pregnant women: An assesssment of rural anganwadi centre and primary health centre
}

\author{
Manoj Kumar, Kusum Bharti and Pramila Prasad
}

The maternal mortality in India is the 56th highest in the world. 42 per cent of births in the country are supervised in Medical Institution. In rural areas, most of women deliver with the help of women in the family, contradictory to the fact that the unprofessional or unskilled deliverer lacks the knowledge about pregnancy. According to the WHO, complications during pregnancy and childbirth are responsible for maternal deaths. In India, the ratio for Maternal Mortality Rate to live births has fallen and by 2015, India plans to reduce its MMR to 109. The objective of the study is, to assess the health and nutritional status of pregnant women of rural anganwadi centre. To assess the nutritional status, Anthropometry Measurement, Maternal and Child health Protection Card, Clinical sign, Haemoglobin, ANC, method and Questionnaire were used.53 per cent women do not get adequate diet whereas only 8 per cent women are getting balance diet. 59 per cent women are not getting supplement diet. Quality and quantity of THR are poor 42 per cent women are not getting IFA and calcium supplementation on their pregnancy period. Only 31 per cent women are benefited with 4 ANC of pregnancy period, 58 per cent women are found severely anaemic, whereas only 20 per cent women are in normal range. 72 per cent women are underweight and 82 per cent are with low BMI. 52 per cent suffering from pregnancy complication. All the above results indicate that most of the pregnant women deprived from proper service of NRHM, ICDS, which are provide in a mission mode for the improvement of health and nutritional status of pregnant women.

Key Words : Antenatal Checkup, Nutrition, Pregnant women, Anaemia, Undernutrition

How to cite this article : Kumar, Manoj, Bharti, Kusum and Prasad, Pramila (2016). Health and nutritional status of pregnant women: An assesssment of rural anganwadi centre and primary health centre. Food Sci. Res. J., 7(1): 130-136. 